\title{
Point-of-care 3D printing: a low-cost approach to teaching carotid artery stenting
}

Pieter De Backer ${ }^{1,2^{*}}$, Charlotte Allaeys ${ }^{3}$, Charlotte Debbaut ${ }^{1}$ and Roel Beelen ${ }^{4}$

\begin{abstract}
Background: Carotid Artery Stenting (CAS) is increasingly being used in selected patients as a minimal invasive approach to carotid endarterectomy. Despite the long standing tradition of endovascular treatments, visual feedback during stent-deployment is impossible to obtain as deployment is performed under fluoroscopic imaging. Furthermore, the concept of stent-placement is often still unclear to patients. 3D Printing allows to replicate patient-specific anatomies and deploy stents inside them to simulate procedures. As such these models are being used for endovascular training as well as patient education.

Purpose: To our knowledge, this study reports the first use of a low-cost patient-specific 3D printed model for teaching CAS deployment under direct visualization, without fluoroscopy.

Methodology: A CT-angiogram was segmented and converted to STL format using Mimics inPrint ${ }^{\mathrm{TM}}$ software. The carotid arteries were bilaterally truncated to fit the whole model on a Formlabs 2 printer without omitting the internal vessel diameter. Next, this model was offset using a $1 \mathrm{~mm}$ margin. A ridge was modelled on the original vessel anatomy which was subsequently subtracted from the offset model in order to obtain a deroofed 3D model. All vessels were truncated to facilitate post-processing, flow and guide wire placement.

Results: Carotid artery stents were successfully deployed inside the vessel. The deroofing allows for clear visualization of the bottlenecks and characteristics of CAS deployment and positioning, including stent foreshortening, tapering and recoil. This low-cost 3D model provides visual insights in stent deployment and positioning, and can allow for patient-specific procedure planning.

Conclusions: The presented approach demonstrates the use of low-cost 3D Printed CAS models in teaching complex stent behavior as observed during deployment. Two main findings are illustrated. On one hand, the feasibility of low-cost in-hospital model production is shown. On the other hand, the teaching of CAS deployment bottlenecks at the carotid level without the need for fluoroscopic guidance, is illustrated. The observed stent characteristics as shown during deployment are difficult to assess in radiologic models. Furthermore, printing patient-specific 3D models preoperatively could possibly assist in accurate patient selection, preoperative planning, case-specific training and patient education.
\end{abstract}

Keywords: Carotid Artery Stenting, 3D Printing, Training, Surgical Education, Phantom

\footnotetext{
* Correspondence: predback.debacker@ugent.be

'IBiTech-bioMMeda, Ghent University, Ghent, Belgium

${ }^{2}$ Orsi Academy, Melle, Belgium

Full list of author information is available at the end of the article
}

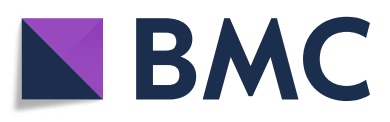

(c) The Author(s). 2021, corrected publication 2021. Open Access This article is licensed under a Creative Commons Attribution 4.0 International License, which permits use, sharing, adaptation, distribution and reproduction in any medium or format, as long as you give appropriate credit to the original author(s) and the source, provide a link to the Creative Commons licence, and indicate if changes were made. The images or other third party material in this article are included in the article's Creative Commons licence, unless indicated otherwise in a credit line to the material. If material is not included in the article's Creative Commons licence and your intended use is not permitted by statutory regulation or exceeds the permitted use, you will need to obtain permission directly from the copyright holder. To view a copy of this licence, visit http://creativecommons.org/ licenses/by/4.0/. The Creative Commons Public Domain Dedication waiver (http://creativecommons.org/publicdomain/zero/1. 0/) applies to the data made available in this article, unless otherwise stated in a credit line to the data. 


\section{Introduction \\ Background}

Carotid artery stenosis affects $10 \%$ of the population by the age of 80, and is associated with an increased risk of cerebrovascular events with major consequences on physical and neurological level [1-3]. Worldwide, carotid revascularization is advised for stroke prevention in moderate or severe carotid stenosis [4]. The revascularization can be performed by carotid endarterectomy (CEA) or Carotid Artery Stenting (CAS) [5, 6]. CEA, i.e. removal of the atherosclerotic plaque via a neck incision, has been the standard treatment since the early fifties $[1$, $7-10]$. The introduction of endovascular carotid techniques 3 decades ago [11] demarked a shift towards the less invasive CAS approach $[7,9]$.

CAS is shown to be a safe long term alternative to CEA in symptomatic carotid stenosis for patients under 70 years, provided that both CEA and CAS are technically feasible [12]. CAS is associated with a slightly lower risk for periprocedural myocardial infarction when compared to CEA [6]. However, CAS is associated with a higher risk of stroke or death within 30 days of treatment, mostly attributable to an increase in periprocedural stroke in patients older than 70 years.

Today's vascular surgery shifts towards minimal invasive techniques because of advantages such as shorter recovery periods, decreased postoperative pain and discomfort, smaller incisions, and shorter in-hospital stays $[8,9]$. Particularly for CAS, a shorter recovery period, less procedural discomfort and an enhanced physical function in the first post-operative year is observed [9, 13]. CAS is preferred over CEA in specific indications including prior history of radiotherapy or neck dissection, contralateral laryngeal nerve damage, contralateral carotid occlusion, re-stenosis after CEA, and in case of high risk for surgery due to comorbidities $[2,3,6,9]$. A more recent approach to transfemoral CAS is a transradial access. Even newer is the transcarotid artery revascularization (TCAR). In TCAR, the carotid artery is directly accessed endovascularly through a small incision in the neck and flow reversal is applied to avoid procedural distal embolization, which is one of the main concerns in CAS. Thus, TCAR can also avoid unfavorable aortic arch anatomy which can be a bottleneck in transfemoral CAS.

\section{Patient selection and preoperative planning}

CT-angiogram (CTA) is often considered the gold standard in non-invasive carotid imaging and diagnosis [14]. Although new techniques allow for enhanced virtual 3D projections on a $2 \mathrm{D}$ computer display, these are not always readily available. Interpretation and visualization of complex cases is aided by converting the CTA to a 3D printed model [15]. 3D models facilitate the geometrical and spatial understanding of the arterial tree, especially in case of anatomical variants, high tortuosity and abnormalities of the carotid artery [16]. Ideally, a patient-specific 3D model could enhance the patient selection and the pre-operative planning by enhancing the surgeon's understanding of the patient-specific 3D anatomy $[17,18]$.

The patient's understanding on the other side, is often very limited due to the technical nature of CAS, and a lack of medical background. As such, patients do often not entirely comprehend the procedure they will undergo and can hardly estimate the involved risks [16]. Informing the patient based on his/her 3D model instead of twodimensional (2D) imaging, as well as adding tactile 3D information to the planar CT imaging, leads to better patient education and enhance informed consent $[16,17]$.

\section{Training of CAS}

To mitigate the increased stroke risk in CAS, it thus seems imperative to further optimize this endovascular technique through training, proper patient selection and pre-operative planning [7]. Outcomes in CAS are shown to be heavily dependent on operator training and skill [19] and CAS attempts by inexperienced surgeons lead to predictable poor results [20]. As such, the hospital and surgeon CAS volume is a major determining factor in the clinical outcome $[7,21]$.

Little training and poor technical skills lead to higher complication rates, higher fluoroscopy, increased nephrotoxic contrast volume usage, and longer procedural durations $[1,9]$. Hence, besides being fully credential in peripheral endovascular techniques, hands-on training is necessary to enhance clinical proficiency for this specific endovascular procedure $[1,5,9]$. During carotid stenting teaching, awareness needs to be created on procedure specific features such as stent foreshortening, recapping, tapering, recoil and jumping of the proximal stent end. Dual layer carotid stents can shorten up to $28 \%$ in length during deployment [22], which is crucial for correct positioning. This final positioning can be difficult to objectivate or estimate on 2D fluoroscopy for trainees. Recoil and jumping of the stent are very brief events and as such these might also be less easily objectivated during fluoroscopy.

Nowadays, training is based on endovascular simulation modules and industry-sponsored courses $[1,5,9$, 23]. These courses can provide a shortened learning curve, address specific features and hence may limit complications [1, 7]. Planning and practicing on 3D printed patient-specific models preoperatively can as such facilitate a straightforward approach by reducing $\mathrm{X}$-ray exposure reduce and operation time [24]. To our knowledge, in hospital training is rarely done due to lacking infrastructure and lacking knowledge in the fabrication of cost-efficient models. 
Due the increased use of 3D Printing in healthcare, a shift towards in-hospital 3D Printing services is taking place globally. More hospitals start to insource 3D Printing, driven by the increased printer performance, lower production costs, shorter time-to-product and easy-touse 3D editing programs. A particular use case of this so-called Point-Of-Care printing is the pretreatment printing of vascular anatomy in support of endovascular procedures.

The current research trend focusses on building simulations for fluoroscopic evaluation but no work has been done in visualising CAS bottlenecks with the naked eye, without fluoroscopy. In this paper, we present a costeffective workflow to perform CAS on a patient-specific 3D model without the use of fluoroscopy.

\section{Methodology}

We present the case of an 80 year old male with severe stenosis in the right internal carotid artery, $0.5 \mathrm{~cm}$ cranial of the carotid bifurcation (Fig. 1). The bifurcation is situated $1.5 \mathrm{~cm}$ above the lower border of the mandibula. The preoperative CTA $(0.75 \mathrm{~mm}$ slice thickness, $140 \mathrm{kVp}$ ) was segmented and converted to a $3 \mathrm{D}$ printable .STL format using Mimics ${ }^{\text {Tw }}$ inPrint 3.0 software (Materialise, Leuven, Belgium). In order to print the model with correct internal vessel diameters in our limited desktop build volume, we chose to bilaterally shorten the common carotid arteries (from Fig. 2.A. to B.). We kept the aortic arch in place for a more realistic simulation, and applied a $1 \mathrm{~mm}$ vessel wall thickness. To facilitate stent deployment view in the translucent material, we chose

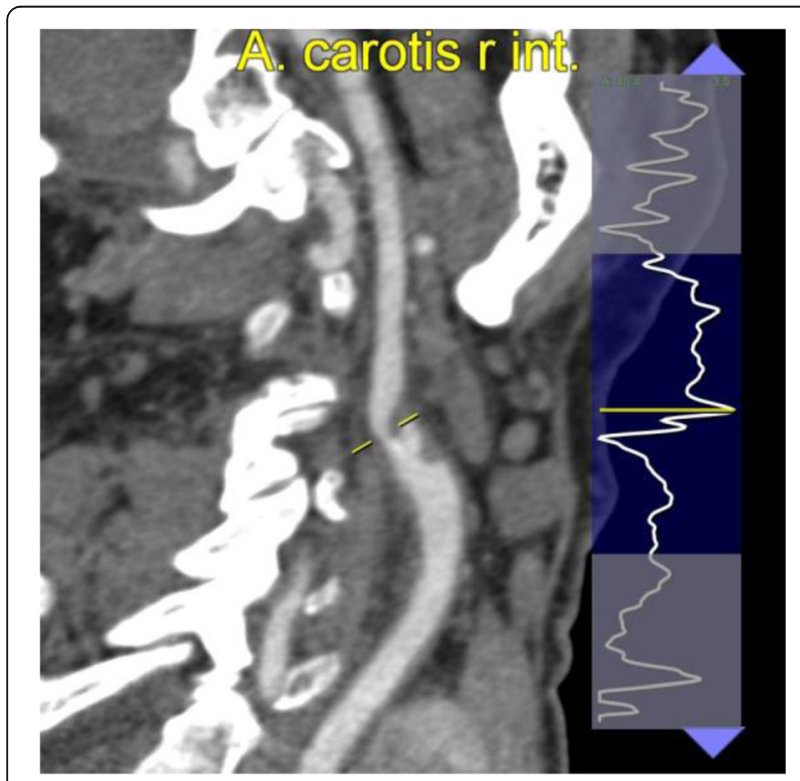

Fig. 1 Cross-sectional sagittal carotid view. Severe carotid artery stenosis at the level of the right internal carotid artery, as indicated by the yellow line to deroof a viewing window at the level of the carotid bifurcation. The deroofing removes $25 \%$ of the circumferential vessel wall and was achieved by modelling a ridge on the original vessel anatomy (Fig. 2.C.), which was subsequently subtracted from the $1 \mathrm{~mm}$ offset model resulting in our final model (Fig. 2.D.). Deroofing allowed for better visual feedback without requiring extra manual post-processing such as sanding or application of coatings which are frequently used to improve translucency after printing.

Truncation, fusion and ridge editing were performed in Meshmixer $^{\mathrm{rm}}$ (Autodesk, California, USA), without omitting the internal vessel diameter. All arterial ends were left open. These open ends serve two goals. On one hand, they allow easy positioning and pull through of guidewires, allowing for a more realistic simulation. On the other hand, they facilitate internal flow of isopropyl alcohol which is used in post-processing to remove non-cured sticky resin.

\section{Results}

The model was printed in one single run on a desktop Formlabs $^{\mathrm{Ta}} 2$ printer (Formlabs, Somerville, Massachusetts, USA) with build volume $145 \times 145 \times 175 \mathrm{~mm}$. Total printing time attained $9 \mathrm{~h} 45 \mathrm{~min}$ with a $0.1 \mathrm{~mm}$ layer thickness. The model was oriented straight as to avoid internal support inside the vessels and was printed with $61.48 \mathrm{ml}$ of standard Clear Formlabs ${ }^{\mathrm{Tx}}$ Resin (Fig. 3).

Figure 4 shows the in-patient stent positioning. A $90 \mathrm{~cm} 5 \mathrm{Fr}$ Terumo $^{\mathrm{Tx}}$. Destination Sheath (Terumo, Tokyo, Japan) and a 0.014 Terumo $^{\text {тm }}$ Gold DT wire was used in the live procedure. The lesion was stented using a Terumo $^{\mathrm{Tm}}$ Roadsaver stent (diameter $7 \mathrm{~mm}$, length $30 \mathrm{~mm}$ ). Post-dilatation was performed using a Boston Scientific $^{\mathrm{Tm}}$ Sterling balloon (diameter $6 \mathrm{~mm}$, length $20 \mathrm{~mm}$ ) after administration of $1 \mathrm{mg}$ atropine.

Figure 5 shows the successful deployment of a dateexpired 5 Fr Nitinol dual layer CAS stent inside the printed model. Deployment was performed without wire or sheat, as the model allowed for direct insertion of the stent delivery catheter inside the model. Deroofing allows for precise visual feedback of important features during CAS implantation. Foreshortening and release of the proximal stent end with accompanying recoil can readily be objectivated (videolink attached). Hence, this model provides unseen insights in stent positioning. It also allows for patient-specific procedure planning. The model was used by 5 experienced CAS surgeons during a workshop who described the tactile feedback as good as real life. This model was also used once in patient education and seemed to be very helpful. Comparison with post-procedure CTA was not performed due to poor renal function. As such, contrast enhanced follow- 


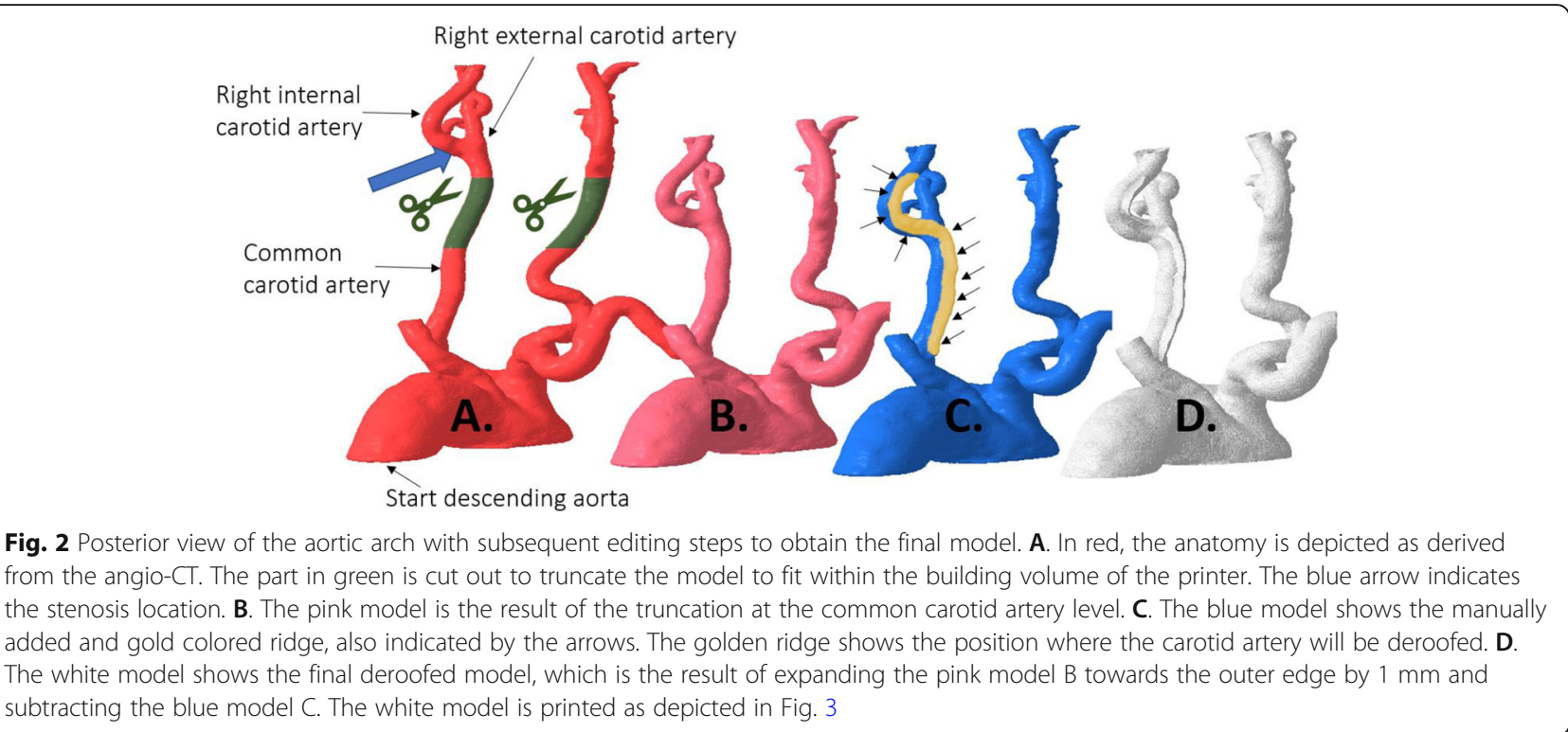

up imaging was avoided and luminal patency was assessed using duplex ultrasound only.

\section{Discussion}

We demonstrate a proof-of-concept low-cost approach to teaching CAS. We specifically focus on objectivating deployment characteristics by direct vision, without fluoroscopy. A 3D printed model of the patient's vascular anatomy including the ostial internal carotid stenosis could contribute to a proper risk factor assessment and surgical-approach analysis, as well as preoperative device sizing. These factors might in turn lead to preventing complications. We might even envision a possibility in extending the CAS indications through refined preoperative training and planning based on patient-specific
3D models. 3D printed models can enable training on difficult anatomical variations which cannot be observed in animal models. Given that CAS-procedure-specificsimulation can shorten the learning curve and lead to better patient outcomes [1], this approach can certainly be relevant in CAS training. In-hospital 3D-printing services can facilitate the introduction of these training models and give more residents access to training with limited costs. Deroofing of the model and accompanying editing steps, might be omitted by manual sanding and coating of the model after printing in an effort to obtain a transparent instead of translucent model. Although we visualize very specific deployment features thanks to our deroofing, this also might impact the stent-vessel interaction to a certain degree. It is however important to

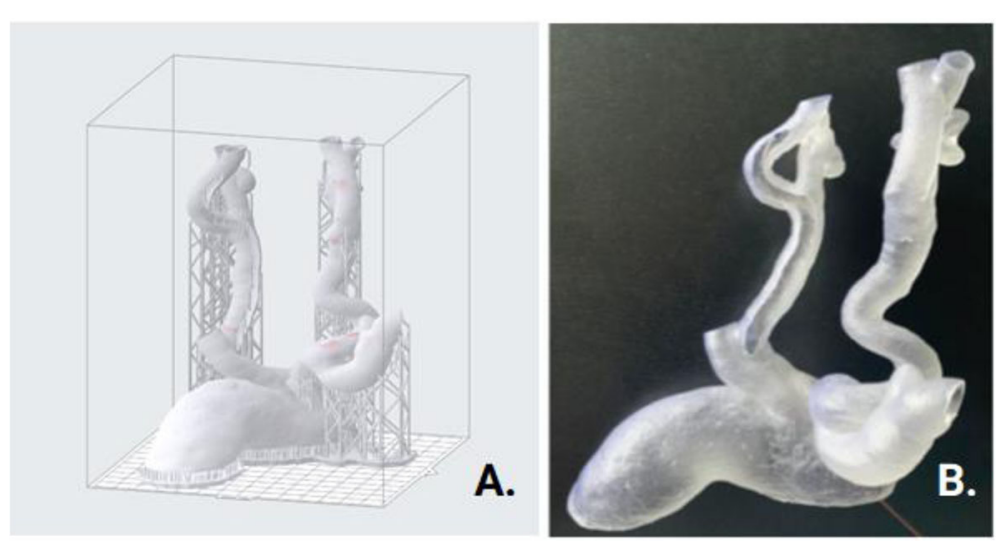

Fig. 3 3D Printing Orientation and Final Model. A. Print build preparation as organized in PreForm ${ }^{\text {TM }}$ (Formlabs, Somerville, Massachusetts, USA). Inside the carotid arteries, support strands are nearly completely avoided using this orientation. After printing, the model is cleaned with isopropyl alcohol and postcured using UV light in a Form Cure ${ }^{\mathrm{TM}}$ module. Next, the outer strands are removed mechanically by hand. B. The 3Dprinted model, with apparent translucency, printed in Clear Formlabs ${ }^{T M}$ Resin. We note the wall of the right carotid artery is left open after deroofing. Catheter sheat is in place within the right internal carotid artery, ready for stent deployment 

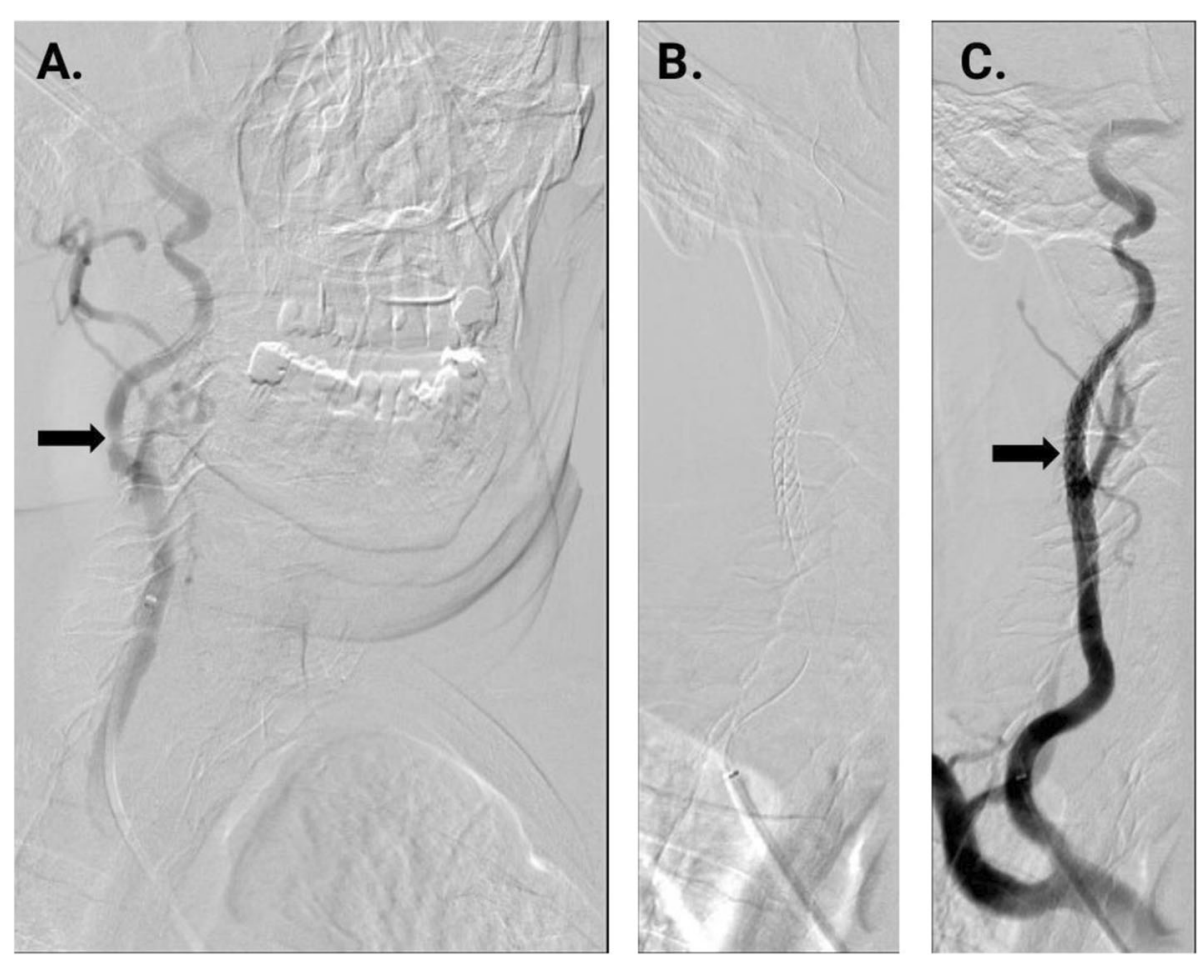

Fig. 4 Stent deployment in vivo. A. High grade stenotic lesion in the right internal carotid artery, as indicated by the arrow. B. After placement of a Terumo ${ }^{\text {TM }}$ Roadsaver stent (diameter $7 \mathrm{~mm}$, length $30 \mathrm{~mm}$ ). C. Angiography shows complete resolution of the stenosis after CAS without dissection of peripheral embolization

note that complete transparency might be hard to reach in UV cured polymers. These polymers tend to yellow out when exposed to daylight too long. As such, a deroofing approach is certainly relevant and avoids the use sanding and application of volatile coatings in a clinical environment.

The time constraint on 3D model development can be avoided by sharing the virtual 'STL' or PreForm ${ }^{\text {rm }}$ files between clinical training centers or co-development.

As this is a proof-of-concept study, it ignites many new opportunities for future research.

One drawback of our model is its rigidity, hence no tissue deformation can occur. Future tests should involve printing in the more recently developed elastic resins and investigate the impact of model deformation. Elastic models can be stretched open and real time flow pre -and post-treatment could then be simulated.

Although patient feedback on this model was positive, systematic patient-questionnaires with different 3D Printed carotid models should be conducted. Systematic trials could be set up to evaluate the effect on preoperative planning, case-selection, stent-sizing or resident training. The focus of this model was on CAS deployment characteristics at the carotid level. Future studies can combine this local feature, with a larger model which also incorporates the descending and abdominal aorta. As such, pitfalls in guidance towards the carotid lesion as well as local pitfalls demonstrated here,

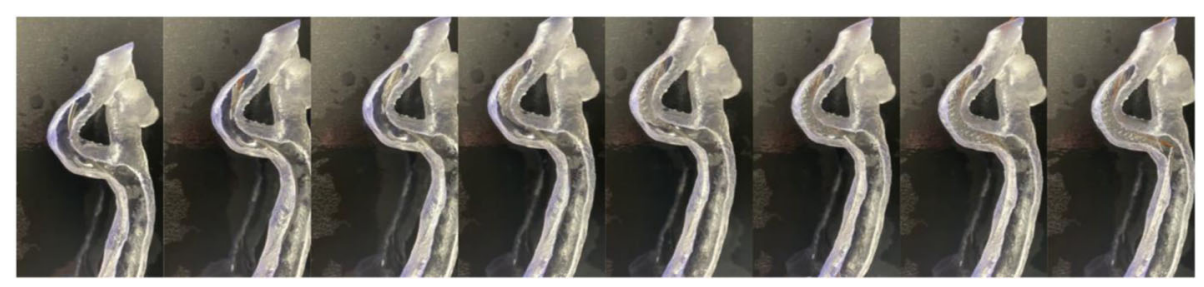

Fig. 5 Stent deployment in silico. Serial series of stent deployment inside the internal carotid artery. The deroofed model allows for precise vision of the deployment, a feature which is not appreciable in completely closed translucent models. The stent is placed more distally to account for foreshortening. In real life, it would otherwise extend into the common carotid artery. We refer to the video in appendix to objectivate other features such as recoil and jumping and the end of deployment 
can be addressed at once. It does need to be taken into account that, to our knowledge, this is not achievable in a cost-effective way or single print due to the small build volume of current desktop SLA printers. Nevertheless, flexible models for TCAR do not need the aortic arch to be printed as these procedures are completely performed at the carotid level. As such, flexible models that can be punctured and sutured, form an interesting research opportunity and alternative for these low-cost CAS training models.

\section{Conclusions}

CAS has a very specific learning curve and currently, no 3D printed models exist to explain the pitfalls during the deployment phase without fluoroscopy. Preoperative patient-specific 3D printed models might enhance the patient's outcome through case-specific training, accurate patient selection and preoperative planning. Patient education might also be improved using these models. Here, we present a framework to generate patientspecific 3D models in the point-of-care setting, which could allow for easier adaptation and implementation of these training models. However, more research is warranted to evaluate the value of these models.

\section{Abbreviations \\ STL: Standard Tessellation Language; CAS: Carotid artery stenting; CEA: Carotid endarterectomy; CT: Computed tomography; 2D: Two- dimensional; 3D: Three-dimensional; CTA: Computed Tomography Angiogram; TCAR: TransCarotid Artery Revascularization}

\section{Supplementary Information}

The online version contains supplementary material available at https://doi. org/10.1186/s41205-021-00119-3.

\section{Additional file 1.}

\section{Acknowledgements}

The article processing charge for this publication has been funded by an unrestricted grant from Materialise.

\section{Authors' contributions}

PDB designed the 3D model, performed the printing and wrote the manuscript together with CA. CD supervised writing. RB provided the clinical case, deployed the stent inside the model as part of an endovascular course, informed the patient using the model and supervised the writing of the manuscript. All authors read and approved the final manuscript.

\section{Funding}

None.

\section{Availability of data and materials}

Video-fragment available: https://drive.google.com/file/d/12 bXLJJeazWQ8JsAhJCb8BQQAOmJQ4RUO/view? usp=sharing.

\section{Declarations}

\section{Authors' information}

PDB is a 3th year urology resident with a master's degree in biomedical engineering. CA is a 4th year medical student at Ghent University with a master degree in physiotherapy. CD is a professor in biomedical engineering (numerical biomechanics) at Ghent University. RB is a thoraco-vascular surgeon at OLV Hospitals.

Ethics approval and consent to participate

Ethics approval by hospital ethics committee reference 2020/140.

Consent for publication

Not applicable.

\section{Competing interests}

The authors declare that they have no competing interests.

\section{Author details}

${ }^{1}$ IBiTech-bioMMeda, Ghent University, Ghent, Belgium. ${ }^{2}$ Orsi Academy, Melle, Belgium. ${ }^{3}$ Faculty of Medicine and Health Sciences, Ghent University, Ghent, Belgium. ${ }^{4} \mathrm{OLV}$ Hospitals Aalst-Asse-Ninove, Ghent, Belgium.

Received: 30 January 2021 Accepted: 15 August 2021

Published online: 02 September 2021

\section{References}

1. Gosling AF, Kendrick DE, Kim AH, Nagavalli A, Kimball ES, Liu NT, et al. Simulation of carotid artery stenting reduces training procedure and fluoroscopy times. J Vasc Surg [Internet]. 2017;66(1):298-306. Available from: https://doi.org/10.1016/j.jvs.2016.11.066.

2. Abbott AL, Paraskevas Kl, Kakkos SK, Golledge J, Eckstein HH, Diaz-Sandoval $\llcorner J$, et al. Systematic Review of Guidelines for the Management of Asymptomatic and Symptomatic Carotid Stenosis. Stroke. 2015;46(11):3288301.

3. Kernan WN, Ovbiagele B, Black HR, Bravata DM, Chimowitz MI, Ezekowitz $M D$, et al. Guidelines for the prevention of stroke in patients with stroke and transient ischemic attack: A guideline for healthcare professionals from the American Heart Association/American Stroke Association. Stroke. 2014; Vol. 45:2160-236 p.

4. Bagley JH, Priest R. Carotid Revascularization: Current Practice and Future Directions. Semin Intervent Radiol. 2020 Jun;37(2):132-9.

5. Rosenfield K, Babb JD, Cates CU, Cowley MJ, Feldman T, Gallagher A, et al. Clinical competence statement on carotid stenting: Training and credentialing for carotid stenting - Multispecialty consensus recommendations: A report of the SCAI/SVMB/SVS Writing Committee to develop a clinical competence statement on carotid interventi. J Am Coll Cardiol [Internet]. 2005;45(1):165-74. Available from: https://doi.org/10.1016/ j.jacc.2004.11.016.

6. Ricotta JJ, Aburahma A, Ascher E, Eskandari M, Faries P, Lal BK. Updated Society for Vascular Surgery guidelines for management of extracranial carotid disease. J Vasc Surg [Internet]. 2011;54(3):e1-31. Available from: https://doi.org/10.1016/j.jvs.2011.07.031.

7. Willaert WIM, Van Herzeele I. Carotid artery stenting - strategies to improve procedural performance and reduce the learning curve. Interv Cardiol. 2013. 8(1):50-6.

8. Saleem T, Baril D. Carotid Artery Stenting. [Internet]. 2020. Available from: https://www.ncbi.nlm.nih.gov/books/NBK470541/.

9. Lin PH, Bush RL, Peden EK, Zhou W, Guerrero M, Henao EA, et al. Carotid artery stenting with neuroprotection: Assessing the learning curve and treatment outcome. Am J Surg. 2005;190(6):855-63.

10. Easton JD. History of carotid endarterectomy then and now: Personal perspective. Stroke. 2014;45(6):101-3.

11. Kachel R, Basche S. Die perkutane transluminale Angioplastik (PTA) von Hirngefäßstenosen (Indikation, Technik, Ergebnisse). In: Schneider GH, Vogler E, editors. Digitale bildgebende Verfahren Interventionelle Verfahren Integrierte digitale Radiologie. Berlin: Springer Berlin Heidelberg; 1988. pp. 192-9.

12. Müller MD, Lyrer PA, Brown MM, Bonati LH. Carotid Artery Stenting Versus Endarterectomy for Treatment of Carotid Artery Stenosis. Stroke. 2020; (January):E3-5

13. Cohen DJ, Stolker JM, Wang K, Magnuson EA, Clark WM, Demaerschalk BM, et al. Health-related quality of life after carotid stenting versus carotid endarterectomy: Results from CREST (Carotid Revascularization Endarterectomy versus Stenting Trial). J Am Coll Cardiol. 2011;58(15):155765. 
14. Heck D, Jost A. Carotid stenosis, stroke, and carotid artery revascularization Prog Cardiovasc Dis [Internet]. 2021;(xxxx):3-8. Available from: https://doi. org/10.1016/.jpcad.2021.03.005.

15. Yang $Y$, Liu X, Xia Y, Wu W, Xiong H, Zhang $H$, et al. Impact of spatial characteristics in the left stenotic coronary artery on the hemodynamics and visualization of 3D replica models. Sci Rep [Internet]. 2017;7(1):1-13. Available from: https://doi.org/10.1038/s41598-017-15620-1.

16. Govsa F, Yagdi T, Ozer MA, Eraslan C, Alagoz AK. Building 3D anatomical model of coiling of the internal carotid artery derived from $C T$ angiographic data. Eur Arch oto-rhino-laryngology Off J Eur Fed Oto-Rhino-Laryngological Soc Affil with Ger Soc Oto-Rhino-Laryngology - Head Neck Surg. 2017; 274(2):1097-102.

17. Petzold R, Zeilhofer HF, Kalender WA. Rapid protyping technology in medicine-basics and applications. Comput Med imaging Graph Off J Comput Med Imaging Soc. 1999:23(5):277-84.

18. Roguin A, Beyar R. Real case virtual reality training prior to carotid artery stenting. Catheter Cardiovasc Interv. 2010;75(2):279-82.

19. Nallamothu BK, Gurma HS, Ting HH, Goodney PP, Rogers M, Curtis M. JP, et al. Operator Experience Carotid Stenting Jama. 2011;306(12):1338-43.

20. Mas JL, Trinquart L, Leys D, Albucher JF, Rousseau H, Viguier A, et al. Endarterectomy Versus Angioplasty in Patients with Symptomatic Severe Carotid Stenosis (EVA-3S) trial: results up to 4 years from a randomised, multicentre trial. Lancet Neurol. 2008;7(10):885-92.

21. Gray WA, Rosenfield KA, Jaff MR, Chaturvedi S, Peng L, Verta P. Influence of site and operator characteristics on carotid artery stent outcomes. JACC Cardiovasc Interv [Internet]. 2011;4(2):235-46. Available from: https://doi. org/10.1016/j.jcin.2010.10.009

22. de Vries EE, Kök M, Hoving AM, Slump CH, Toorop RJ, de Borst GJ. (In)comparability of Carotid Artery Stent Characteristics: A Systematic Review on Assessment and Comparison with Manufacturer Data. Cardiovasc Intervent Radiol. 2020;43(10):1430-7.

23. Willaert W, Aggarwal R, Bicknell C, Hamady M, Darzi A, Vermassen F, et al. Patient-specific simulation in carotid artery stenting. J Vasc Surg 2010;52(6): 1700-5. Available from: https://doi.org/10.1016/j.jvs.2010.08.015.

24. Göccer $H$, Durukan $A B$, Tunç $O$, Naseri E, Ercan E. Evaluation of 3D printed carotid anatomical models in planning carotid artery stenting. Turkish J Thorac Cardiovasc Surg. 2020;28(2):294-300.

\section{Publisher's Note}

Springer Nature remains neutral with regard to jurisdictional claims in published maps and institutional affiliations.

Ready to submit your research? Choose BMC and benefit from:

- fast, convenient online submission

- thorough peer review by experienced researchers in your field

- rapid publication on acceptance

- support for research data, including large and complex data types

- gold Open Access which fosters wider collaboration and increased citations

- maximum visibility for your research: over $100 \mathrm{M}$ website views per year

At $\mathrm{BMC}$, research is always in progress.

Learn more biomedcentral.com/submissions 